\title{
The Love Addiction Inventory: Preliminary Findings of the Development Process and Psychometric Characteristics
}

\author{
Sebastiano Costa ${ }^{1,3}$ (D) Nadia Barberis ${ }^{2}$ - Mark D. Griffiths ${ }^{3} \cdot$ Loredana Benedetto $^{2}$. \\ Massimo Ingrassia ${ }^{2}$
}

Published online: 16 May 2019

(C) The Author(s) 2019

\begin{abstract}
Although the existence of dysfunctional love relationships is well known and the term "love addiction" dates back to the 1970s, empirical studies on this topic are still limited. The biggest problem is arguably is the lack of a clear definition of the love addiction construct and the lack of psychometric instruments for the assessment of its symptoms. The aim of the present study was to develop and examine the psychometric characteristics of a self-report scale assessing love addiction using the components model of behavioral addiction. Two studies based on the splitting of a total sample of 663 participants involved in an intimate relationship (for at least for 6 months) were recruited to examine the psychometric characteristics of the newly developed love addiction scale and its six-item short-form. In the first study, an exploratory factor analysis (EFA) was conducted with a sample of 329 participants. In the second study, a confirmatory factor analysis (CFA) approach was used with a sample of 334 participants engaged in a romantic relationship. In both studies, reliability and concurrent validity were also examined. Results suggested that the factor structure of the Love Addiction Inventory and its six-item short-form is in line with the theoretical framework and showed good reliability and concurrent validity. The LAI in both short and longer forms are psychometrically robust and can be used to assess love addiction in future studies.
\end{abstract}

Keywords Love addiction · Love addiction inventory $\cdot$ Behavioral addiction $\cdot$ Psychometric characteristics

Sebastiano Costa

sebastiano.costa@unicampania.it

1 Dipartimento di Psicologia, Università degli Studi della Campania Luigi Vanvitelli, Viale Ellittico, 31 -, 81100 Caserta, Italy

2 Department of Clinical and Experimental Medicine, University of Messina, Messina, Italy

3 Department of Psychology, Nottingham Trent University, Nottingham, UK 
Being in love with someone is one of the most common feelings that human beings can experience in their lifetime. Many studies have tried to understand and conceptualize the psychology of love, exploring the factors and mechanisms underlying the love construct (Sternberg and Weis 2006). There has also been considerable research interest concerning the more problematic aspects of love relationships (Fisher 2014). When love is characterized by obsession, compulsive behaviors, anxiety, and negative life consequences, it has been viewed by some as love addiction (Kwee 2007; Stanbury and Griffiths 2007). Love addiction has been defined as a compulsive need of relationships that persists despite its adverse consequences (Reynaud et al. 2010). In fact, individuals with love addiction typically show a loss of interest in other activities outside love relationships (e.g., close friends, hobbies, and sport) and academic or work problems due the inability to concentrate on other areas of life (Earp et al. 2017). Individuals addicted to love tend to experience negative moods and affects when away from their partners and have the strong urge and craving to see their partner as a way of coping with stressful situations (Sussman 2010).

The pioneering work on love addiction was first outlined in the book Love and Addiction by Peele and Brodsky (1975). The book described love addiction as a condition that occurs when individuals become dependent in the relationships with those with whom they are most intimately involved. Peele and Brodsky (1975) asserted that the addictive process for love relationships is the same as when a person becomes dependent on a drug. Subsequent studies have evidenced that love addiction shares numerous aspects and features of other behavioral or substance addictions (Fisher 2014; Peele et al. 1992; Sussman 2010, Wolfe 2000). Although, at present, love addiction is not yet embedded in psychiatric nosology, there is increasing recognition of behavioral addictions in the mental health literature, as demonstrated by the gradual incorporation of some behavioral addictions (i.e., gambling disorder, gaming disorder) into the most recent editions of diagnostic manuals such as the Diagnostic and Statistical Manual of Mental Disorders and the International Classification of Diseases (Griffiths et al. 2016).

A comprehensive review by Sussman et al. (2011) on 11 different addictions estimated the prevalence of the love addiction in general adult population from 3 to $6 \%$, with studies reporting widely different percentages of prevalence (from $3 \%$ to $26 \%$ ). The main problem in estimating the prevalence of love addiction was the definition of the construct used by the investigators. Many researchers often used different constructs as a proxy for love addiction (e.g., preoccupation with love, love insecurity, submissive relationship) that although admittedly similar, these constructs do not specifically represent love addiction. Consequently, validated questionnaires to evaluate love addiction symptoms are lacking (Sussman et al. 2011).

Regarding the construct of love addiction, one parsimonious model for describing the characteristics of love addiction is the components model of addiction (Griffiths 2005). This model argues that to be categorized as a genuine behavioral addiction, love addiction would comprise six core dimensions: salience (i.e., the love for an individual is the single most important part of the person' life and all feelings, thoughts and behavior are oriented towards the person they are in love with); tolerance (e.g., the need to spend increasing amounts of time with and/or more time spent thinking about the person they are in love with); mood modification (e.g., being with and/or thinking about the person they are in love with as a way of coping with emotional distress); relapse (i.e., difficulty of stopping or reducing the time spent with and/or thinking about the person they love); withdrawal (i.e., physical and/or psychological withdrawal symptoms when not together with the person they love, such as frustration, irritability, anxiety, nausea, and stomach cramps); and conflict (i.e., their preoccupying love for 
someone interferes with all other life activities such as their occupation/education, friendships with other people, lack of leisure activities and hobbies, etc.).

Although the components model of addiction is well validated and broadly recognized in international behavioral addiction literature, it has not been applied in the field of affective dependence (such as love addiction). Although a few scales have been developed to assess love addiction, they are now outdated and/or do not have not a strong theoretical foundation. For example, the Love Addiction Scale (LAS) was developed by Hunter et al. (1981), which was subsequently superseded the Passionate Love Scale (PLS) by Hatfield, and Sprecher (1986). More recently, Feeney and Noller (1990) developed an unnamed 12-item scale comprising two subscales: reliance on partner and unfulfilled hopes. However, none of these scales is widely used and they assess dependence on an ideal love, rather than love addiction (Sussman 2010). Other populist scales are available online that assess love addiction symptoms such as the love addiction quiz (Gaba 2018), love addiction self-assessment (Falango 2012), and the 40 questions of sex and love addicts Anonymous (Augustine Fellowship 1985). However, despite their ease of use, these scales have not been published in peer-reviewed journals, contain no information concerning the psychometric characteristics, and there are no theoretical underpinnings or constructs outlined.

Given these many limitations of existing instruments, a psychometrically robust scale that assesses love addiction using a strong theoretical framework that is in line with recent developments on behavioral addictions is warranted. Consequently, the aim of the present study was to develop a psychometrically robust self-report scale to assess love addiction using a strong theoretical framework (i.e., the components model of addiction; Griffiths 2005). This newly developed scale - the ILove Addiction Inventory (LAI) — was designed by creating 24 items, four for each of the six dimensions of addiction defined by Griffiths (2005): salience, tolerance, mood modification, relapse, withdrawal, and conflict. These dimensions have been widely used in many scales assessing other behavioral addictions including addictions (among others) to work (e.g., Andreassen et al. 2012a), gaming (Lemmens et al. 2009; Costa et al. 2019), social media (Andreassen et al. 2012b; Orosz et al. 2016b), exercise (Terry et al. 2004), shopping (Andreassen et al. 2015), television series watching (Orosz et al. 2016a), sex (Andreassen et al. 2018a), pornography (Böthe et al. 2018), and tanning (Andreassen et al. 2018b). Additionally, a short-form of the LAI was developed using only one item from each dimension and examining the factor structure, reliability, and concurrent validity of both versions.

Given that the present study was the first to be conducted using the LAI, as recommended in the statistical literature, exploratory factor analysis (EFA) and confirmatory factor analysis (CFA) were conducted via two different sets of analyses using different samples (Kline 2005). In the present study, a total sample of participants who at the time of data collection were involved in an intimate relationship (for at least for 6 months) and the sample was split into two to carry out the separate EFA and CFA. The first study explored the factor structure of the new LAI using exploratory factor analysis (EFA) and testing the reliability and concurrent validity of the instrument. Negative mood states (i.e., affective states) are usually experienced as a consequence of behavioral addictions (e.g., Costa et al. 2013; Matthews et al. 2009; Vidyachathoth et al. 2014), and love addiction is also related to mood disorder (Reynaud et al. 2010). Consequently, to test the concurrent validity of the LAI, correlations with positive and negative affect were tested. Furthermore, as an additional test for concurrent validity, LAI scores were correlated with the Love Addiction Self-Assessment criteria (LASA; Falango 2012). The second study explored the factor structure of the LAI attained in the first study 
using confirmatory factor analysis (CFA), as well as replicating the reliability and concurrent validity of the instrument. It was hypothesized that the psychometric characteristics of the LAI in the first study would be similar to the second study.

\section{Method (Study 1)}

\section{Participants}

A total sample of 663 participants were collected and then randomly split into two different sub-samples for the EFA in study $1(n=329)$ and the CFA in Study $2(n=334)$. In Study 1 , the 329 participants who completed an online questionnaire comprised 19 males and 310 females, and their age ranged between 18 and 43 years $(M=23.16 ; \mathrm{SD}=2.77)$. All the participants were Italian and Italian was their first language. They also reported as having at least one romantic partner lasting at least 6 months up to a maximum of 24 years $(\mathrm{M}=4.21$ years; $\mathrm{SD}=$ 3.06). Most of the participants were currently in relationship $(n=287 ; 87 \%), 34$ participants lived together with their partner (10\%), and eight participants were married to their partner (3\%). Most of participants were students $(n=250 ; 76 \%), 37$ participants had a temporary job (11\%), 18 participants had permanent job (5\%), and 12 had independent jobs (4\%). Regarding education, most of the participants had a university degree $(n=170 ; 52 \%), 156$ participants had a high school diploma (47\%), and three participants had a middle school diploma (1\%). Only six participants had children (2\%), while the remaining 323 participants did not have children $(98 \%)$.

\section{Procedure}

The Love Addiction Inventory (LAI) was developed by creating four items for each criterion of behavioral addictions (i.e., salience, tolerance, mood modification, relapse, withdrawal, and conflict) described above. The wording used for item generation was similar to that used in previous questionnaires on behavioral addictions (e.g., Andreassen et al. 2012a, b, 2015; Lemmens et al. 2009). The research team recruited a convenience sample for the study by publicizing a link to an online survey to psychology students, and asking them to circulate it also via their own social networks and online groups. The inclusion criteria were to have been in a relationship with a romantic partner for at least 6 months and be aged over 18 years. Instructions clearly stated that (i) completing the survey was voluntary, (ii) responses were confidential, and (iii) anonymity was guaranteed. The study was performed in accordance with the ethical standards of the Declaration of Helsinki, and the completion of the survey took approximately 15 minutes to complete.

\section{Measures}

Demographic Information Demographic information was requested including specific questions concerning gender, age, education level, first language, relationship status, and the length of time in a relationship.

Love Addiction Inventory To develop the Love Addiction Inventory (LAI), four items for each criterion of the addiction components model (i.e., salience, tolerance, mood modification, 
relapse, withdrawal, and conflict) were created (Griffiths 2005). All the items began with the phrase "How often do you...", and participants rated their response according to a 5-point Likert scale: 1 (never), 2 (rarely), 3 (sometimes), 4 (often), and 5 (very often). Higher scores indicate higher levels of love addiction symptoms. The original items are reported in Table 1, with the respective criteria and corresponding English translations.

Positive and Negative Affect Schedule (PANAS; Watson et al. 1988) The PANAS is a widely used 20-item self-report measure comprising 10 positive emotion items and 10 negative emotion items. The 5-point Likert scale ranges from 1 (very slightly) to 5 (extremely). Previous studies have reported good psychometric characteristics (Terraciano et al. 2003; Watson et al. 1988), and in the present study, the obtained alpha indices for both PANAS subscales were high (positive affect: $\alpha=.84$; negative affect, $\alpha=.85$ ).

Love Addiction Self-assessment To have a concurrent measure of love addiction, the Love Addiction Self-Assessment (LASA; Falango 2012) was used. The LASA comprises 25 items answered using a "yes/no" dichotomy, and is freely available on the internet. The LASA was adapted from the "40 questions for self-diagnosis" (Augustine Fellowship 1985). Although the LASA is used by clinical practitioners, no previous studies have ever examined its psychometric characteristics. In the present study, the LASA obtained a moderate alpha index $(\alpha=.62)$.

\section{Results (Study 1)}

\section{Descriptive Analyses and Preliminary Analyses}

Table 1 shows the means and standard deviations for all the items of the LAI. Skewness and kurtosis for all the items were also determined and some items were somewhat positively or negatively skewed. Furthermore, a variant of Smalls' omnibus test of multivariate normality (DeCarlo 1997) was significant (VQ3[48] $=687.21, p<.001$ ), indicating multivariate nonnormality of the data. Inter-item correlations ranged from .09 to .84 in absolute value (Table 2). A Kaiser-Meyer-Olkin (KMO) measure of sampling adequacy was tested, showing an excellent value of .92 , suggesting the factorability of the correlations matrix.

\section{Exploratory Factor Analysis}

To verify the factorial structure of the LAI, principal axis factoring was conducted with the Kaiser normalization promax rotation. The use of EFA in a first study testing a new construct (i.e., love addiction in this case) is more suitable (Schmitt 2011). Furthermore, the use of principal axis factoring is recommended with a violation of the assumption of multivariate normality (Costello and Osborne 2005; Fabrigar et al. 1999).

The number of factors was determined through Velicer's minimum average partial (MAP) test and parallel analysis (Velicer 1976; Velicer et al. 2000). Both the parallel analysis and the original MAP test suggested six factors, and for this reason, a principal axis factoring estimation using promax rotation with a six-factor solutions was used to explore factor loadings. The six-factor solution was found to explain $74 \%$ of the variance (eigenvalues for 
Table 1 Items description

Item

Component

1. Sentire il bisogno urgente di incontrarti con il/la tuo/a partner [Feel the urgent need to meet with your partner]

2. Provare la necessità urgente di vederti con i1/la tuo/a partner [Try to urgently see your partner]

3. Sentire la necessità urgente di stare insieme al/la tuo/a partner [Feel the urgent need to be with your partner]

4. Sentire l'urgenza di stare in compagnia del/la tuo/a partner [Feel the urgency of wanting to be in the company of your partner]

5. Sentirti agitato/a quando non sei insieme al tuo/a partner [Feel agitated when you are not with your partner]

6. Sentirti ansioso/a quando non sei in compagnia del/la tuo/a partner [Feel anxious when you are not in the company of your partner]

7. Sentirti depresso/a in assenza del/la tuo/a partner [Feel depressed in your partner's absence]

8. Sentirsi abbandonato/a quando non sei con il/la tuo/a partner [Feel abandoned when you are not with your partner]

9. Sentire il bisogno di aumentare la quantità di tempo che trascorri con il/la tuo/a partner per provare un adeguato piacere [Feel the need to increase the amount of time you spend with your partner to experience pleasure]

10. Sentire il bisogno di aumentare gli incontri con il/la tuo/a partner per sentirti felice [Feel the need to increase the number of meetings with your partner to feel happy]

11. Sentire il bisogno di aumentare i momenti in compagnia del/la tuo/a partner per sentirti appagato/a [Feel the need to increase the number of meetings in the company of your partner to feel satisfied]

12.Sentire il bisogno di aumentare il tempo passato insieme al/la tuo/a partner per provare serenità [Feel the need to increase the time spent together with your partner to feel relaxed]

13. Stare con il/la tuo/a partner per alleviare lo stress [Stay with your partner to relieve stress]

14. Passare del tempo con il/la tuo/a partner per scordarti delle tue sofferenze [Spend time with your partner to forget about your suffering]

15. Vederti con il/la tuo/a partner per evitare di essere di cattivo umore [Spend time with your partner to avoid being in a bad mood]

16. Stare con il/la tuo/a partner per ridurre i tuoi sentimenti negativi [Spend time with your partner to reduce your negative feelings]

17. Non riuscire a passare meno tempo con il/la tuo/a partner [Fail to spend less time with your partner]

18. Non essere in grado di ridurre la durata degli incontri con il/la tuo/a partner [Fail in reducing the duration of meetings with your partner]

19. Fallire nel tentativo di evitare di incontrarti con il/la tuo/a partner [Fail to avoid meetting with your partner]

20. Non farcela a ridurre i momenti da passare con il/la tuo/a partner [Not reduce the time spent with your partner]

21. Abbandonare $\mathrm{i}$ tuoi hobby per stare insieme al/la tuo/a partner [Abandon your hobbies to be with your partner]

22. Rinunciare alle tue attività ricreative e sociali per impegnarti nella relazione con il/la tuo/a partner [Leave your recreational and social activities to be in a relationship with your partner]

23. Tralasciare i tuoi impegni familiari e sociali a causa del rapporto con il/la tuo/a partner [Discard your family and social commitments due to the relationship with your partner]

24. Trascurare il tempo di studio o di lavoro per impegnarti nella relazione con il/la tuo/a partner [Neglect time studying or working to be in the relationship with your partner]

Salience

Salience

Salience

Salience

Withdraw

Withdraw

Withdraw

Withdraw

Tolerance

Tolerance

Tolerance

Tolerance

Mood Mod

Mood Mod

Mood Mod

Mood Mod

Relapse

Relapse

Relapse

Relapse

Conflict

Conflict

Conflict

Conflict

the first ten factors were $10.20,2.78,1.61,1.25,0.94,0.78,0.63,0.55,0.53)$. Factor loadings examination also showed a clear factor structure (Table 3 ), with high principal factor loadings (from .38 to .93) and minimal cross-factor loadings between different factors (none greater 
than .19). Furthermore, all the 24 items loaded into the expected factors. All these results suggest that the six-factor solution is an appropriate factorial structure for the Love Addiction Inventory and provides evidence for the theoretical organization of the items relating to the six addiction components (i.e., salience, tolerance, mood modification, relapse, withdrawal, and conflict).

\section{Composite Scores, Internal Reliability, and Correlation for Concurrent Validity}

Descriptive analyses and correlation of the composite score of the LAI were conducted (Table 4). All six subscales of the LAI were positively and significantly related to each other, and they were positively correlated with the concurrent measure of the LASA and negatively related with the negative affect measure. The positive affect measure was negatively related with symptoms of withdrawal, tolerance, and conflict. In addition, the composite score of the LAI was negatively related to positive affect and positively related with the LASA and negative affect. Cronbach's alpha values for all the subscales and the total score were high with a range from .77 to .95 .

\section{6-Item Love Addiction Inventory-Short-Form}

To obtain a short-form of the LAI, an EFA with a principal axis factoring estimation using a single-factor solutions was used. The items with the highest overall measurement loadings from each of the six factors were selected for the 6-item Love Addiction Inventory-Short-Form (LAI-SF). The selected items were LAI 3 (.82) from salience, LAI 7 (.73) from withdrawal, LAI 12 (.76) from tolerance, LAI 13 (.61) from mood modification, LAI 20 (.62) from relapse, and LAI 24 (.49) from conflict. An additional EFA with a principal axis factoring estimation using a single-factor solution was used with only the six items of the LAI-SF, showing high factor loadings (Table 5). Cronbach's alpha value was high (.82), and the composite score LAI-SF showed a significant positive correlation with the composite score of the full-form, all the subscales of the full-form, the LASA, and negative affect. The correlation with positive affect was not significant.

\section{Method (Study 2)}

\section{Participants}

A total of 334 participants (18 males and 316 females) ranged in age between 18 and 31 years $(\mathrm{M}=22.71$ years; $\mathrm{SD}=2.26)$ completed the online questionnaire. All the participants were Italian and Italian was their first language. They also reported as having at least one romantic partner lasting at least 6 months up to a maximum of 24 years $(\mathrm{M}=$ 4.29; $\mathrm{SD}=3.57)$. Most of the participants were in a relationship $(n=300 ; 90 \%), 28$ participants lived together with their partner $(8 \%)$, and six participants were married to their partner $(2 \%)$. Furthermore, most of participants were students $(n=283 ; 85 \%), 30$ participants had a temporary job (9\%), nine participants had permanent job (3\%), nine had independent jobs (3\%), and seven were unemployed (2\%). Regarding education, most of the participants had degree $(n=166 ; 50 \%), 165$ participants had a high school diploma 


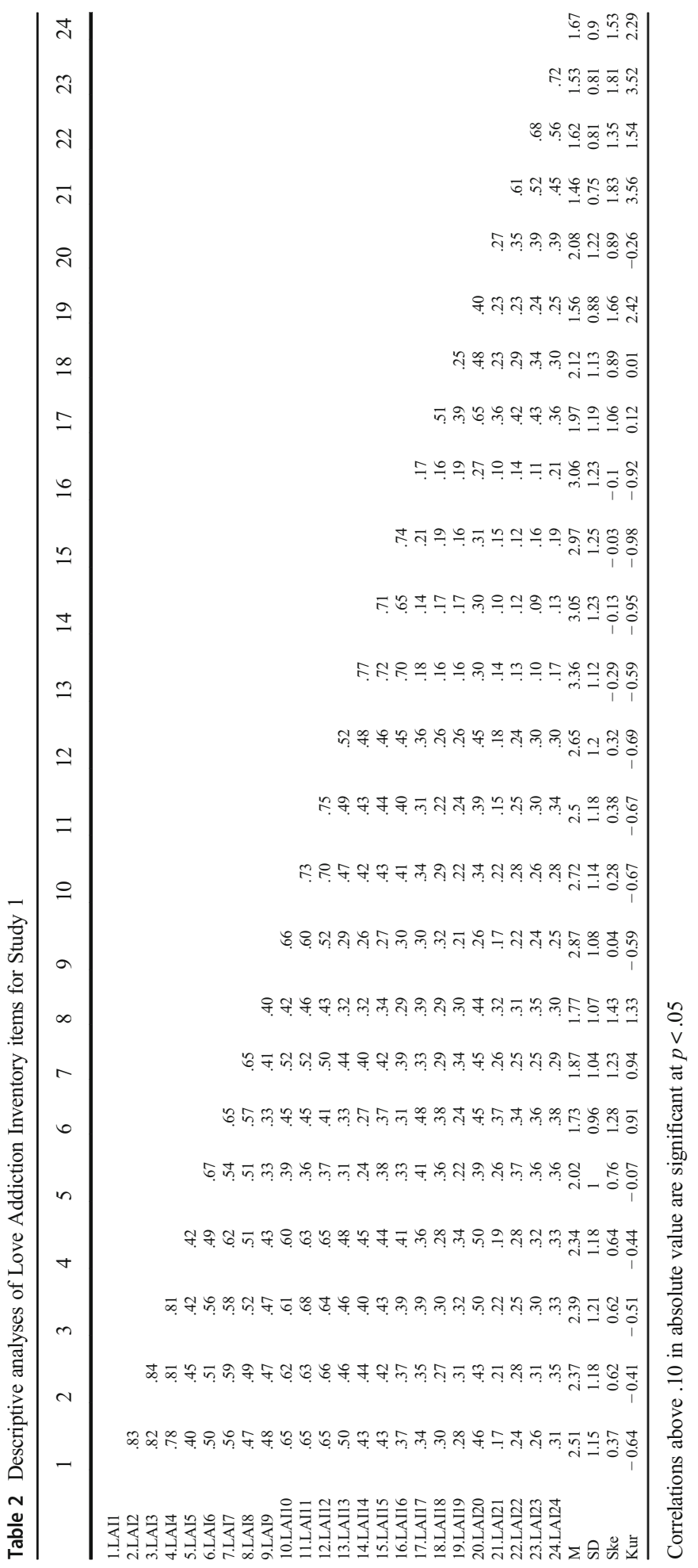


Table 3 Exploratory factor analyses for Study 1

\begin{tabular}{|c|c|c|c|c|c|c|c|c|}
\hline & Salience & Mood modification & Conflict & Tolerance & Relapse & Withdrawal & $h^{2}$ & $u^{2}$ \\
\hline LAI1 & .85 & -.02 & -.04 & .09 & .01 & -.01 & .80 & .20 \\
\hline $\mathrm{LAI} 2$ & .93 & -.04 & .05 & -.01 & -.08 & .05 & .83 & .17 \\
\hline LAI3 & .88 & -.05 & -.03 & .00 & .04 & .07 & .83 & .17 \\
\hline LAI4 & .89 & .03 & .02 & -.07 & .03 & .02 & .80 & .20 \\
\hline LAI5 & -.08 & .05 & .08 & .03 & .04 & .68 & .55 & .45 \\
\hline LAI6 & .04 & -.03 & .03 & -.02 & .03 & .82 & .73 & .27 \\
\hline LAI7 & .25 & .06 & -.09 & .03 & -.03 & .65 & .67 & .33 \\
\hline LAI8 & .14 & -.01 & .03 & .05 & .04 & .56 & .52 & .48 \\
\hline LAI9 & -.09 & -.09 & -.03 & .80 & .05 & .07 & .55 & .45 \\
\hline LAI10 & .05 & .03 & .00 & .83 & -.03 & .03 & .79 & .21 \\
\hline LAI11 & .26 & .05 & .03 & .65 & -.05 & -.03 & .74 & .26 \\
\hline LAI12 & .30 & .15 & .01 & .50 & .09 & -.13 & .69 & .31 \\
\hline LAI13 & .07 & .85 & -.01 & .01 & -.03 & -.03 & .77 & .23 \\
\hline LAI14 & .07 & .86 & -.02 & -.05 & .02 & -.08 & .71 & .29 \\
\hline LAI15 & -.08 & .87 & .01 & -.04 & -.01 & .11 & .75 & .25 \\
\hline LAI16 & -.11 & .84 & .02 & .04 & .00 & .03 & .67 & .33 \\
\hline LAI17 & -.12 & -.07 & .03 & .08 & .84 & .04 & .71 & .29 \\
\hline LAI18 & -.14 & -.02 & .01 & .13 & .57 & .09 & .38 & .62 \\
\hline LAI19 & .18 & .01 & .03 & -.07 & .37 & .01 & .23 & .77 \\
\hline LAI20 & .21 & .08 & -.02 & -.13 & .78 & -.06 & .68 & .32 \\
\hline LAI21 & -.10 & .03 & .61 & -.05 & .00 & .17 & .43 & .57 \\
\hline LAI22 & -.04 & .00 & .81 & .02 & .00 & .02 & .65 & .35 \\
\hline LAI23 & .05 & -.04 & .89 & .00 & .02 & -.07 & .78 & .22 \\
\hline LAI24 & .10 & .02 & .73 & .00 & -.01 & -.03 & .58 & .42 \\
\hline Eigenvalue & 10.20 & 2.78 & 1.61 & 1.25 & 1.05 & 0.94 & & \\
\hline$\%$ Variance & $43 \%$ & $12 \%$ & $7 \%$ & $5 \%$ & $4 \%$ & $4 \%$ & & \\
\hline
\end{tabular}

Italic values indicate the items loading on each factor

(49\%), and three participants had a middle school diploma (1\%). Only six participants had children (2\%), while the remaining participants did not have children $(n=329 ; 98 \%)$.

\section{Procedure and Measures}

The procedure and measures were the same as described in the first study. The same materials were used as in Study 1 (demographic information, the Love Addiction Inventory, the Positive and Negative Affects Schedule, and the Love Addiction Self-Assessment). In the second sample, the obtained alpha indices for both the PANAS subscales were high (positive affect, $\alpha=.85$; Negative Affect, $\alpha=.88)$ whereas for the LASA it was moderate $(\alpha=.59)$.

\section{Results (Study 2)}

\section{Descriptive Analyses and Preliminary Analyses}

Table 6 shows the means, standard deviations, skewness, and kurtosis for all the items of the LAI. The examination of the skewness and kurtosis showed that some items were somewhat positively or negatively skewed. Furthermore, a variant of Smalls' omnibus test of multivariate 


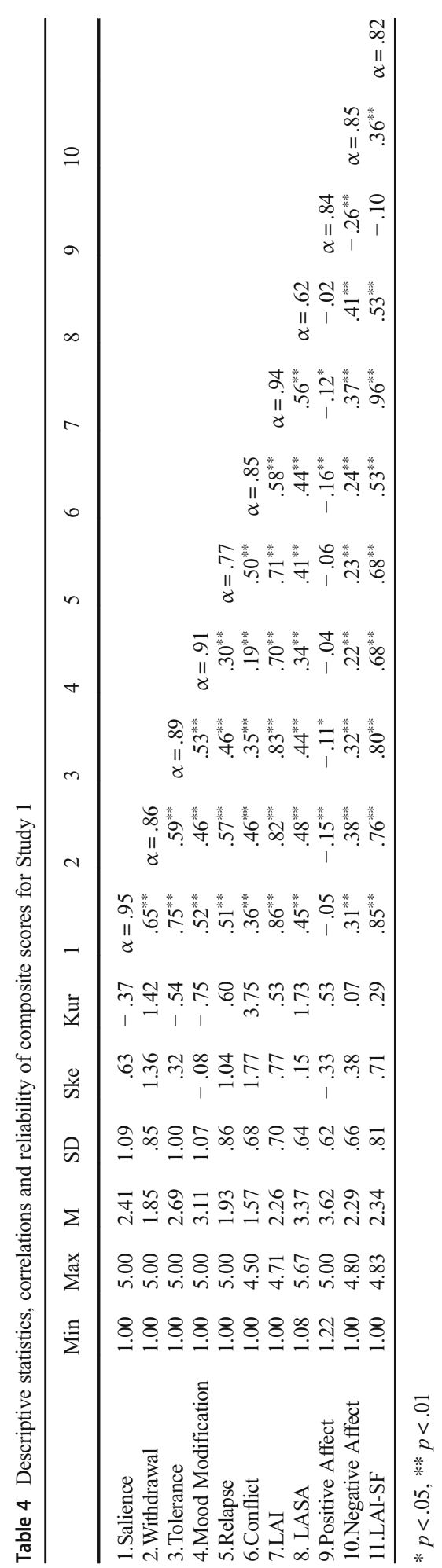


Table 5 Factor loading for the EFA of Study 1 and the CFA of Study 2

Factor loading

EFA Study 1
Factor loading CFA Study 2

LAI3 (salience)
LAI7 (withdrawal)
LAI12 (tolerance)
LAI13 (mood modification)
LAI20 (relapse)
LAI24 (conflict)

$\begin{array}{ll}.81 & .79 \\ .70 & .66 \\ .77 & .77 \\ .58 & .61 \\ .62 & .54 \\ .42 & .36\end{array}$

normality (DeCarlo 1997) was significant (VQ3[48] $=771.94, p<.001)$, indicating a multivariate non-normality of the data. Inter-item correlations ranged from .07 to .78 in absolute value.

\section{Confirmatory Factor Analysis}

A CFA was conducted to test a second-order hierarchical model, that is, one represented by a higher-order second-order factor that account for the six symptoms of love addiction (firstorder factors), and that each symptom comprises four items of the LAI. The Satorra-Bentler scaling correction to the maximum likelihood $\chi^{2}$, and the robust maximum likelihood methods for fit indices were used because the data departed significantly from multivariate normality. The second-order hierarchical model had acceptable fit with the data, $\chi^{2}(246)=668.17$, $p<.01, \mathrm{~S}-\mathrm{B} \chi^{2}(246)=556.90, \mathrm{R}-\mathrm{CFI}=.93, \mathrm{R}-\mathrm{RMSEA}(90 \% \mathrm{CI})=.07(.06-.08), \mathrm{SRMR}=.07$, and all the standardized factor loadings were significant $(p<.01)$ and ranged from .49 to .89 (Table 7).

\section{Composite Scores, Internal Reliability, and Correlation for Concurrent Validity}

Descriptive analyses and correlation of the composite score of the LAI for Study 2 are reported in Table 8. All the six subscales of the LAI and the composite score of love addiction were positively and significantly related to each other, and they were positively correlated with the LASA and with the negative affect measure. The positive affect measure was negatively related with the composite score of the LAI, and with the symptoms of withdrawal, relapse, and conflict. Cronbach's alpha values for all the subscales and the total score were high with a range from .76 to .94 .

\section{6-Item Love Addiction Inventory-Short-Form}

In Study 2, the 6-item Love Addiction Inventory-Short-Form (LAI-SF) was also tested, using only one item for each factor and testing the model with a single latent factor comprising the six items selected in Study 1 as indicators. The CFA used to test the model indicated that a single-factor model solution fitted the data well, $\chi^{2}(9)=49.00, p<.01$; S-B $\chi^{2}(9)=36.80$, $p<.01$; R-CFI = .94; RMSEA = .11 $(90 \% \mathrm{CI}=.07-.15)$; SRMR $=.06)$, and all the standardized factor loadings were significant $(p<.01)$ and ranged from .36 to .79 (Table 5). Cronbach's alpha value was high (.79) and the composite score LAI-SF showed significance positive correlation with the composite score of the full-form, all the subscales of the full-form, the LASA, and negative affect. The correlation with positive affect was not significant. 


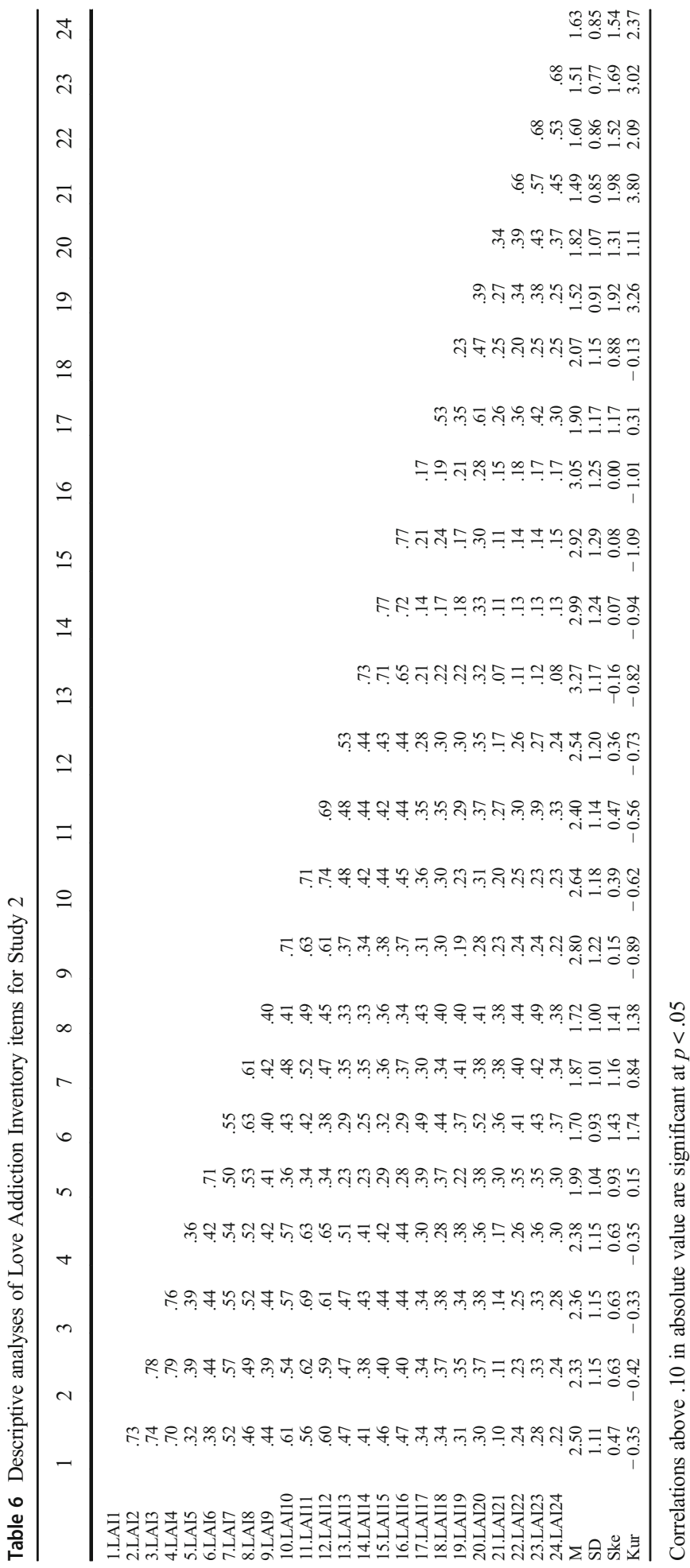


Table 7 Confirmatory factor analyses for Study 2

Factor loading

Measurement error

\begin{tabular}{|c|c|c|}
\hline \multicolumn{3}{|l|}{ Salience } \\
\hline LAI1 & .82 & .32 \\
\hline LAI2 & .89 & .21 \\
\hline LAI3 & .89 & .21 \\
\hline LAI4 & .87 & .24 \\
\hline \multicolumn{3}{|l|}{ Withdrawal } \\
\hline LAI5 & .72 & .48 \\
\hline LAI6 & .80 & .36 \\
\hline LAI7 & .75 & .43 \\
\hline LAI8 & .78 & .39 \\
\hline \multicolumn{3}{|l|}{ Tolerance } \\
\hline LAI9 & .76 & .43 \\
\hline LAI10 & .87 & .24 \\
\hline LAI11 & .84 & .30 \\
\hline LAI12 & .83 & .31 \\
\hline \multicolumn{3}{|l|}{ Mood modification } \\
\hline LAI13 & .81 & .35 \\
\hline LAI14 & .87 & .24 \\
\hline LAI15 & .89 & .20 \\
\hline LAI16 & .84 & .30 \\
\hline \multicolumn{3}{|l|}{ Relapse } \\
\hline LAI17 & .77 & .42 \\
\hline LAI18 & .64 & .59 \\
\hline LAI19 & .49 & .76 \\
\hline LAI20 & .77 & .40 \\
\hline \multicolumn{3}{|l|}{ Conflict } \\
\hline LAI21 & .69 & .53 \\
\hline LAI22 & .80 & .36 \\
\hline LAI23 & .88 & .24 \\
\hline LAI24 & .73 & .47 \\
\hline \multicolumn{3}{|c|}{ LAI (hierarchical factor) } \\
\hline Salience & .85 & .27 \\
\hline Withdrawal & .85 & .29 \\
\hline Tolerance & .84 & .29 \\
\hline Mood modification & .62 & .61 \\
\hline Relapse & .73 & .48 \\
\hline Conflict & .56 & .69 \\
\hline
\end{tabular}

\section{Discussion}

The main aim of the two studies was to develop a psychometrically robust instrument to assess love addiction, based on the strong theoretical framework of the components model of addiction (Griffiths 2005). The present study described the development of the LAI as a new instrument to assess love addiction using four items as indicators of each of the six addiction component (i.e., salience, tolerance, mood modification, relapse, withdrawal, and conflict). Two studies were conducting with the LAI, examining the factor structure (using both EFA and CFA), reliability, and concurrent validity. The second aim of the study was also to develop a short-form of the questionnaire using only one item from each subscale to develop a six-item short-form of the LAI (i.e., the LAI-SF). Furthermore, all the subscales and the total scores of the LAI (full-form and short-form) showed significant positive correlations with negative affect and the score of love addiction as assessed using the LASA. Results showed 


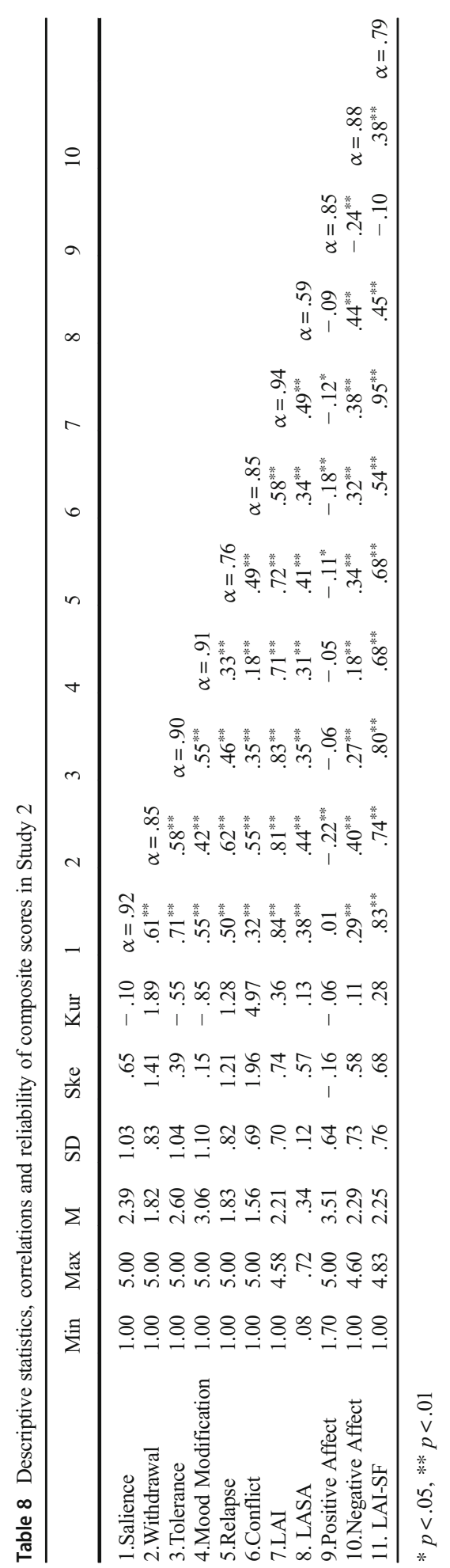


that both the full-form and the short-form appear to be useful tools for the general assessment of love addiction and the specific criteria in the components model of behavioral addictions (Griffiths 2005).

The LAI was developed creating four items for each component. The choice of four items is ideal (Chen et al. 2015) because, in future studies, it allows the opportunity to perform SEM analyses with latent variables (a minimum of three indicators per latent construct is generally recommended; Kline 2005), but is concise enough for a wide use in combination with other psychometric instruments. Furthermore, having four items per factor allows for further examination that would cross-validate the LAI in different cultures and allows the removal of one item in case of problems with specific items in a particular language version. The shortform with only one item for each component is also similar to most of the instruments assessing other behavioral addictions (e.g., Andreassen et al. 2012a, b, 2015; Lemmens et al. 2009).

In the first study, an EFA was conducted to explore the factor structure of the 24 items that comprised the LAI. Results suggested a structure of six factors (each with four items) that clearly reflect the core components of addiction (i.e., salience, tolerance, mood modification, relapse, withdrawal, and conflict). This structure was also confirmed in the second study, using a CFA that provided evidence for a second-order hierarchical structure, suggesting that each group of four items loaded correctly in each corresponding latent factor (i.e., salience, tolerance, mood modification, relapse, withdrawal, and conflict), and that all the six firstorder factors load on a higher-order general factor of love addiction. Furthermore, in both the studies, the single-factor structure of the short-form of the LAI (created selecting a single item with the highest loading from each factor of the first study) was tested. Results demonstrated that the 6-item short-form version of the LAI showed good factorial structure and there were consistent outcomes across the two samples. This is a confirmation of previous studies (Kuss et al. 2014; Terry et al. 2004) on the application of the components model of addiction (Griffiths 2005) in assessing behavioral addiction, and extending it (for the first time) to love addiction.

All the six components and the total composite score of love addiction showed good internal reliability in both studies reported here. Cronbach's alpha coefficients above .70 are usually indication of a reliable set of items (De Vaus 2002), and in these two studies, all the factors were above the .70 cut-off score with a range between .76 and .95 . The short-form of the LAI also showed also good reliability level with alpha of .82 in Study 1 and .79 in Study 2. These results provide support for the robust psychometric characteristics of the LAI, whereas the other instrument used in the present study for assessing love addiction (i.e., the LASA) had low reliability values. In light of this, the LAI appears to have the necessary characteristics to adequately assess love addiction overcoming the limitations of the previous instruments. Concurrent validity was examined in both Study 1 and Study 2, verifying the relationships of LAI subscales, the total scores of both the full-form and the short-form LAI, and the LASA and the PANAS. All the six components and the total scores of the LAI were positively related with the score on the LASA and negative affect. The correlations with positive affect instead were negatively significant only for some scales, confirming that negative affect has a strong relation with addictions (Kassel et al. 2007; Matthews et al. 2009; Wood and Williams 2007). The present results are also in line with the general tendency of love addicted individuals to maintain their relationships despite the negative consequences, and to use such relationships to cope with negative affect (Coppolino, Ingrassia, Benedetto, and Aguglia 2015; Reynaud et al. 2010). In general, both the full-form and the short-form of the LAI were shown to be extremely 
related with similar constructs providing further support to the robustness of the instrument's validity.

Several limitations are present in this study. First, the participants comprised a convenience sample with a high proportion of females due to the fact that many of the respondents were students enrolled in courses in psychology (a subject that generally has a higher concentration of females, particularly in Italy where the present survey was carried out). Even though it is a common practice in psychological research, future studies should extend these results on larger and more heterogeneous samples to explore the generalizability of the LAI. Second, the present survey was performed in an online version. Although previous studies (Hohwü et al. 2013; Van De Looij-Jansen and De Wilde 2008; Weigold et al. 2018) have clearly shown that paper-pencil and online questionnaires provide the same results, future studies should replicate these findings in a more structured setting. Third, all the concurrent measures were self-report and there were no external criteria for the validity, so further studies need to extend the psychometrics characteristics of the LAI also using observational and/or behavioral-based measures. Fourth, the LAI assesses love addiction as a continuous variable and did not allow the defining of a cut-off to identify at-risk or addicted individuals. Future studies could try to identify the characteristics of clinical samples to test also the clinical validation of the LAI. Finally, in the present study, the short-form of the LAI was obtained from the best scoring the items in the full-form. Future studies should also use the six-item short-form to extend and confirm the results of the present study.

Despite these limitations, the present study demonstrated that the LAI has good psychometrics characteristics and will be a useful assessment tool for the assessment of love addiction. Furthermore, this study is an important first step in promoting the development of research concerning love addiction. The operationalization process of love addiction via the well-established components model of addiction (Griffiths 2005) and the availability of an instrument with robust psychometric characteristics will help to overcome the obstacles that have limited research of this field of study.

\section{Compliance with Ethical Standards}

Conflict of Interest The authors declare that they have no conflict of interest.

Open Access This article is distributed under the terms of the Creative Commons Attribution 4.0 International License (http://creativecommons.org/licenses/by/4.0/), which permits unrestricted use, distribution, and reproduction in any medium, provided you give appropriate credit to the original author(s) and the source, provide a link to the Creative Commons license, and indicate if changes were made.

\section{References}

Andreassen, C. S., Griffiths, M. D., Hetland, J., \& Pallesen, S. (2012a). Development of a work addiction scale. Scandinavian Journal of Psychology, 53, 265-272.

Andreassen, C. S., Torsheim, T., Brunborg, G. S., \& Pallesen, S. (2012b). Development of a Facebook addiction scale. Psychological Reports, 110, 501-517.

Andreassen, C. S., Griffiths, M. D., Pallesen, S., Bilder, R. M., Torsheim, T., \& Aboujaoude, E. (2015). The Bergen shopping addiction scale: Reliability and validity of a brief screening test. Frontiers in Psychology, 6 , 1374 . 
Andreassen, C. S., Pallessen, S., Griffiths, M. D., Torsheim, T., \& Sinha, R. (2018a). The development and validation of the Bergen-Yale Sex Addiction Scale with a large national sample. Frontiers in Psychology, 9 , 144.

Andreassen, C. S., Pallesen, S. Torsheim, T., Demetrovics, Z. \& Griffiths, M. D. (2018b). Tanning addiction: Conceptualization, assessment, and correlates. British Journal of Dermatology. Epub ahead of print. https://doi.org/10.1111/bjd.16480 .

Augustine Fellowship (1985). 40 questions for diagnosis. Retrieved from: https://slaafws.org/download/corefiles/The 40 Questions of SLAA.pdf. Accessed 3 Aug 2018.

Bőthe, B., Tóth-Király, I., Zsila, Á., Demetrovics, Z., Griffiths, M. D., \& Orosz, G. (2018). The development of the problematic pornography consumption scale (PPCS). Journal of Sex Research, 55, 395-406.

Chen, B., Vansteenkiste, M., Beyers, W., Boone, L., Deci, E. L., Van der Kaap-Deeder, J., et al. (2015). Basic psychological need satisfaction, need frustration, and need strength across four cultures. Motivation and Emotion, 39, 216-236.

Coppolino, P., Ingrassia, M., Benedetto, L., \& Aguglia, E. (2015). Measuring addictive relationships in couples: Psychometric properties of the Italian version of the Cuestionario de Dependencia Emocional. Psicoterapia Cognitiva e Comportamentale, 21(3), 303-318.

Costa, S., Hausenblas, H. A., Oliva, P., Cuzzocrea, F., \& Larcan, R. (2013). The role of age, gender, mood states and exercise frequency on exercise dependence. Journal of Behavioral Addictions, 2, 216-223.

Costa, S., Barberis, N., Gugliandolo, M. C., Liga, F., Cuzzocrea, F., \& Verrastro, V. (2019). Examination of the psychometric characteristics of the Italian version of the Game Addiction Scale for Adolescents. Psychological Reports. https://doi.org/10.1177/0033294119838758 .

Costello, A. B., \& Osborne, J. W. (2005). Best practices in exploratory factor analysis: Four recommendations for getting the most from your analysis. Practical Assessment, Research \& Evaluation, 10, 1-9.

De Vaus, D. (2002). Analyzing social science data: 50 key problems in data analysis. London: Sage.

DeCarlo, L. T. (1997). On the meaning and use of kurtosis. Psychological Methods, 2, 292-307.

Earp, B. D., Wudarczyk, O. A., Foddy, B., \& Savulescu, J. (2017). Addicted to love: What is love addiction and when should it be treated? Philosophy, Psychiatry, and Psychology, 24, 77.

Fabrigar, L. R., Wegener, D. T., MacCallum, R. C., \& Strahan, E. J. (1999). Evaluating the use of exploratory factor analysis in psychological research. Psychological Methods, 4, 272-299.

Falango, M. (2012). Love addiction self-assessment. Retrieved August 3, 2018, from: http://markfalango. com/wp-content/uploads/2012/05/lasa.pdf.

Feeney, J. A., \& Noller, P. (1990). Attachment style as a predictor of adult romantic relationships. Journal of Personality and Social Psychology, 58, 281-291.

Fisher, H. E. (2014). The tyranny of love: Love addiction — an anthropologist's view. In K. Rosenberg \& L. Feder (Eds.), Behavioral addictions: criteria, evidence and treatment (pp. 237-265). New York: Elsevier.

Gaba, S. (2018). Love addiction quiz. Retrieved August 3, 2018, from: http://sherrygaba.com/love-addictionquiz/.

Griffiths, M. (2005). A 'components' model of addiction within a biopsychosocial framework. Journal of Substance Use, 10, 191-197.

Griffiths, M. D., Kuss, D. J., Pontes, H. M., \& Billieux, J. (2016). Where do gambling and internet 'addictions' belong? The status of 'other' addictions. In K. Wolff, J. White, \& S. Karch (Eds.), The SAGE handbook of drug and alcohol studies (Vol. 2, pp. 446-470). London: Sage.

Hatfield, E., \& Sprecher, S. (1986) Measuring passionate love in intimate relationships. Journal of Adolescence, 9(4), 383-410

Hohwü, L., Lyshol, H., Gissler, M., Jonsson, S. H., Petzold, M., \& Obel, C. (2013). Web-based versus traditional paper questionnaires: a mixed-mode survey with a Nordic perspective. Journal of Medical Internet Research, 15, e173-e180.

Hunter, M. S., Nitschke, C., \& Hogan, L. (1981). A scale to measure love addiction. Psychological Reports, 48, $582-582$

Kassel, J. D., Greenstein, J. E., Evatt, D. P., Roesch, L. L., Veilleux, J. C., Wardle, M. C., \& Yates, M. C. (2007). Negative affect and addiction. In J. D. Kassel, J. E. Greenstein, D. P. Evatt, L. L. Roesch, J. C. Veilleux, M. C. Wardle, \& M. C. Yates (Eds.), Stress and addiction: Biological and psychological mechanism (pp. 171189). San Diego: Elsevier Academic Press.

Kline, T. (2005). Psychological testing: A practical approach to design and evaluation. Thousand Oaks: Sage.

Kuss, D. J., Shorter, G. W., van Rooij, A. J., Griffiths, M. D., \& Schoenmakers, T. M. (2014). Assessing internet addiction using the parsimonious internet addiction components model - A preliminary study. International Journal of Mental Health and Addiction, 12, 351-366.

Kwee, A. W. (2007). Constructing addiction from experience and context: Peele and Brodsky's love and addiction revisited. Sexual Addiction \& Compulsivity, 14, 221-237. 
Lemmens, J. S., Valkenburg, P. M., \& Peter, J. (2009). Development and validation of a game addiction scale for adolescents. Media Psychology, 12, 77-95.

Matthews, N., Farnsworth, B., \& Griffiths, M. D. (2009). A pilot study of problem gambling among student online gamblers: Mood states as predictors of problematic behavior. Cyberpsychology \& Behavior, 12, 741745 .

Orosz, G., Bőthe, B., \& Tóth-Király, I. (2016a). The development of the problematic series watching scale (PSWS). Journal of Behavioral Addictions, 5(1), 144-150.

Orosz, G., Tóth-Király, I., Böthe, B., \& Melher, D. (2016b). Too many swipes for today: The development of the problematic tinder use scale (PTUS). Journal of Behavioral Addictions, 5(3), 518-523.

Peele, S., \& Brodsky, A. (1975). Love and addiction. Oxford: Taplinger.

Peele, S., Brodsky, A., \& Arnold, M. (1992). Truth about addiction and recovery. New York: Fireside.

Reynaud, M., Karila, L., Blecha, L., \& Benyamina, A. (2010). Is love passion an addictive disorder? American Journal of Drug and Alcohol Abuse, 36, 261-267.

Schmitt, T. A. (2011). Current methodological considerations in exploratory and confirmatory factor analysis. Journal of Psychoeducational Assessment, 29, 304-321.

Stanbury, A., \& Griffiths, M. D. (2007). Obsessive love as an addiction. Psychology Review, 12(3), 2-4.

Sternberg, R. J., \& Weis, K. (2006). The new psychology of love. Yale: Yale University Press.

Sussman, S. (2010). Love addiction: definition, etiology, treatment. Sexual Addiction \& Compulsivity, 17, 31-45.

Sussman, S., Lisha, N., \& Griffiths, M. (2011). Prevalence of the addictions: a problem of the majority or the minority? Evaluation \& the Health Professions, 34, 3-56.

Terraciano, A., McCrae, R. R., \& Costa, P. T., Jr. (2003). Factorial and construct validity of the Italian positive and negative affect schedule (PANAS). European Journal of Psychological Assessment, 19(2), 131-141.

Terry, A., Szabo, A., \& Griffiths, M. D. (2004). The Exercise Addiction Inventory: A new brief screening tool. Addiction Research and Theory, 12, 489-499.

Van De Looij-Jansen, P. M., \& De Wilde, E. J. (2008). Comparison of web-based versus paper-and-pencil selfadministered questionnaire: Effects on health indicators in Dutch adolescents. Health Services Research, 43, $1708-1721$.

Velicer, W. F. (1976). Determining the number of components from the matrix of partial correlations. Psychometrika, 41, 321-327.

Velicer, W. F., Eaton, C. A., \& Fava, J. L. (2000). Construct explication through factor or component analysis: A review and evaluation of alternative procedures for determining the number of factors or components. In R. D. Goffin \& E. Helmes (Eds.), Problems and solutions in human assessment (pp. 41-71). Boston: Springer.

Vidyachathoth, K. B., Kumar, N. A., \& Pai, S. R. (2014). Correlation between affect and internet addiction in undergraduate medical students in Mangalore. Journal Addiction Research \& Therapy, 5, 1-4.

Watson, D., Clark, L. A., \& Tellegen, A. (1988). Development and validation of brief measures of positive and negative affect: The PANAS scales. Journal of Personality and Social Psychology, 54, 1063-1070.

Weigold, A., Weigold, I. K., \& Natera, S. N. (2018). Mean scores for self-report surveys completed using paperand-pencil and computers: A meta-analytic test of equivalence. Computers in Human Behavior, 86, 153164.

Wolfe, J. L. (2000). Assessment and treatment of compulsive sex/love behavior. Journal of Rational-Emotive \& Cogntive-Behavior Therapy, 18, 235-246.

Wood, R. T., \& Williams, R. J. (2007). Problem gambling on the Internet: Implications for Internet gambling policy in North America. New Media \& Society, 9, 520-542.

Publisher's Note Springer Nature remains neutral with regard to jurisdictional claims in published maps and institutional affiliations. 